\title{
La vida cotidiana del inmigrante español en Cuba, 1920-1940
}

\section{Consuelo Naranjo Orovio}

Los acontecimientos mundiales, posguerra y crisis económicas, ocurridos durante el periodo analizado fueron determinantes para el desarrollo económico de Cuba y, por tanto, para el proceso migratorio hacia la isla, así como para la colectividad española allí asentada. Los dos momentos clave que estudiaremos son 1921 y 1929 , por ser éstos los de mayor trascendencia, tanto para el país como para la colonia española, pues generaron nuevos procesos, de los cuales la colectividad española fue uno de los protagonistas: repatriaciones y adopción de la nacionalidad cubana.

Tras el auge azucarero que se produjo en Cuba como consecuencia de la primera Guerra Mundial, por ser éste el proveedor de azúcar de los países en litigio, sobrevino una aguda crisis económica que tuvo su primera manifestación en el nivel bancario. El fin de la guerra trajo consigo la liberalización de los precios del azúcar. Mientras la zafra de 1919 fue vendida a 5.06 centavos la libra, la de 1920 lo fue a 11.95 centavos, precio que descendió súbitamente a finales de ese mismo año con la aparición en el mercado mundial de nuevos productores. Así, en 1921 la zafra fue vendida a 3.10 centavos la libra. ${ }^{1}$

La llamada "Danza de los Millones" - que dio lugar a la época de las "vacas gordas", durante la cual se multiplicaron las inversiones y se crearon una gran variedad de instituciones bancarias y crediticias, nacidas a la sombra de este rápido e irreal desarrollo económico- había tocado a su fin. Uno de nuestros entrevistados nos comenta así los hechos:

La peor época, las "vacas flacas", porque ese azúcar que valió a veinticinco centavos, valió luego menos de un centavo. . después de 1920 , cuando vino aquella caída de los precios y de acuerdo con el precio del azúcar se redujo la vida en Cuba; porque antes, en la época de las "vacas gordas", todo el mundo vivía bien, vaya, y después de esto, muy apretaos, porque no había, porque no habia, no valian las cosas. Aqui el azúcar, aquí, la vida de aquí era el azúcar; en aquella época no había industria cubana, los zapatos venían de fuera, la ropa venía de fuera, todo venía de fuera. ${ }^{2}$

La crisis general se hizo manifiesta cuando los bancos cubanos declararon la suspensión de pagos. La alarma comenzó el 9 de octubre de 1920, tras anunciar el Banco Internacional la suspensión de todas las operaciones al no haber podido hacer efectivo un cheque. Situaciones similares se sucedieron en otras instituciones bancarias como el Banco Nacional y el Banco Español de la Isla de Cuba. El 10 de octubre, el gobierno cubano dictó el Decreto sobre Moratoria

1 Ramiro Guerra, op. cit., 1970; Julio Le Riverend, La República, La Habana, Editorial Ciencias Sociales, 1973.

2 Entrevista núm. 322, La Habana, octubre de 1983. 
Núm. 1583, por el cual las letras de cambio, giros, pagarés y otros documentos de crédito, vencidos y que vencieran hasta el próximo 1 de diciembre, no se harían efectivos sino en esa fecha; por otra parte, los depositantes de los bancos sólo podían pedir en las cuentas corrientes hasta $10 \%$ de sus depósitos, mientras que las cuentas menores de dos mil pesos podían exigir $12 \% .^{3}$ A este decreto se sucedieron otros, como el Decreto Núm. 1861, de 27 de noviembre de 1920, por el cual se prorrogaba la moratoria concedida en el decreto anterior hasta el 31 de diciembre; y el Decreto Núm. 2006, del 31 de diciembre, que una vez más ampliaba el plazo de la moratoria hasta el 31 de enero de $1921^{4}$ Las disposiciones contenidas en estos decretos fueron anuladas por la Ley de Moratoria del 27 de enero de 1921, por la cual las acciones procedentes de obligaciones comerciales de carácter mercantil no podrían renegociarse hasta después de pasados 105 días naturales desde que la ley comenzase a regir; por otra parte, los depositantes de los bancos no podrían reclamar sus depósitos hasta pasados 135 días desde que la ley comenzase a regir. ${ }^{5}$

Esta crisis bancaria afectó tanto a los grandes propietarios, industriales y hacendados, como a los propietarios de pequeñas cuentas corrientes, como eran la mayoría de los miembros de la colectividad española. Uno de los afectados por la crisis comenta ló siguiente:

Vino la quiebra de los bancos y hubo mucho español perjudicado con aquello, entre ellos yo. Tenía cuenta en dos bancos, en el Banco Español y en el Banco Nacional, y se perdió mucho. Se perdió un diez por ciento de lo que había. ${ }^{6}$

Tras el crack bancario y la inexistencia de crédito, se produjo un descenso de los salarios, acompañado de una disminución en los puestos de trabajo. Ante esta situación, una de las primeras medidas adoptadas por el ministro español en Cuba fue la de dirigir una circular a cada uno de los cónsules, vicecónsules y agentes consulares de España en la isla, en la que les solicitaba información sobre las consecuencias de la crisis en la colectividad española, y especialmente sobre aquellos ingenios que hubieran dejado de pagar los salarios a los trabajadores españoles. Ante el resultado alarmante de la encuesta, el representante español instó a las autoridades españolas a que se suprimiese la emigración a Cuba, al menos hasta que la situación se normalizase, o bien, que como medio para evitar males mayores, se difundiese entre los posibles emigrantes el nombre de los ingenios que, en esas circunstancias, podían continuar pagando a sus trabajadores; a la vez, pedía el envío a Cuba de un delegado del Consejo Superior de Emigración, el cual se encargaría de recibir a los emigrantes y conducirlos a los centrales aún solventes. ${ }^{7}$

3 Decreto núm. 1583, dado en el palacio de la presidencia, La Habana, el 10 de octubre de 1920, por el presidente Mario García Menocal. Decretos sobre Moratoria, publicados en la Gaceta Oficial, Extraordinaria, de 10 de octubre y 30 de noviembre de 1920, respectivamente, La Habana, Imprenta y Papelería de Rambla, Bouza y Cía, 1920.

Ibidem.

5 Ley de Moratoria de 27 de enero de 1921, La Habana, Imprenta y Papelería de Rambla, Bouza y Cía. 1921.

6 Entrevista núm. 315, La Habana, octubre de 1983.

7 Despacho enviado por el ministro de S.M., desde La Habana, el 19 de junio de 1921. AGAAH, AE, caja 1697. 
Los informes consulares de esta época no cesan de ser alarmantes y presentan un panorama desolador sobre la indigencia de muchos españoles; solicitaban se llevasen a cabo repatriaciones, se concediesen nuevos créditos para ello, se autorizase una prolongación del tiempo de ayuda que los consulados podían dar a cada individuo, así como para que se paralizase la emigración a Cuba ${ }^{8} \mathrm{Algu}$ nas de estas peticiones fueron atendidas y discutidas por el Consejo Superior de Emigración a instancias del ministro de Estado. ${ }^{9}$

La situación creada en el medio rural produjo a su vez la migra. ción de los indigentes hacia las ciudades, con lo cual las asociaciones de beneficencia y el Consulado, sobre todo en la capital, se vieron desbordados sin poder atender a todas las demandas de repatriación. El Consulado fue el encargado de repartir los medios pasajes, los cuales, según dictaba la ley de emigración, obligaban a las compañías navieras a repatriar $20 \%$ de los inmigrantes españoles que hubieran conducido al país receptor, durante el año anterior, a mitad de precio. ${ }^{10}$ Todo ello produjo escenas que se repetían frecuentemente, protagonizadas por miles de españoles jornaleros que esperaban ante el edificio del Consulado de España en La Habana ser uno de los beneficiados por el medio pasaje. Por otra parte, el elevado precio de los pasajes dificultaba aún más la tarea, por lo cual los presidentes de las sociedades de beneficencia, reunidos en el Consulado de España, acordaron enviar dos cartas, una al ministro de Estado de España y otra al marqués de Comillas, en Barcelona, a fin de que el pasaje de tercera fuera rebajado a la mitad y se fijase su precio en 60 dólares. ${ }^{11}$

Muchas sociedades de beneficencia españolas albergaron en sus hospitales a indigentes, tal es el caso del Centro Asturiano, en su hospital La Covadonga; la Asociación de Dependientes de Comercio, en la Purísima Concepción; el Centro Gallego, en La Benéfica. . ., etc. A pesar de todos los esfuerzos, éstos no fueron suficientes, por lo que el cónsul español tuvo que recurrir a las autoridades cubanas a fin de que le permitieran la instalación en Triscornia de españoles a cambio de una dieta de 80 centavos por persona, en cuyo pago el Consulado era ayudado por el Centro Gallego. ${ }^{12}$

${ }^{8}$ Véanse los informes y telegramas enviados desde Cuba a lo largo de 1921 sobre la situación de los españoles dedicados a las tareas agrícolas, minas. . etc., y las gestiones del Consulado de España en La Habana a favor de la elevación del número de repatriaciones mediante las compañías navieras, y la autorización de nuevos créditos; "se solicitan $\$ 5000$,. .etc." AMAE, Correspondencia Consulados, H. 1914, 19191924.

9 Carta enviada desde el Ministerio de Estado al ministro de España en La Habana, Madrid, 17 de junio de 1921. AGAAH, AE, caja 1697.

10 A manera de ejemplo citamos los fondos destinados para repatriaciones y socorros por la Sociedad de Beneficencia Asturiana a lo largo de 1921, que ascendieron a $\$ 16$ 726.05. Sociedad de Beneficencia Asturiana, Memoria 1877-1977, La Habana, 1977, p. 36-37. Informe remitido desde el Consulado español de La Habana, el 18 de junio de 1926, AGAAH, AE, caja 1694.

"La Discusión, 10 y 11 de junio, La Habana, 1921; La Lucha, 7, 9, 10, 12 y 14 de junio, La Habana, 1921; El Mundo, 8 y 22 de junio, La Habana, 1921; Diario Español, 11, 14 y 28 de junio, La Habana, 1921, AMAE, R. 748, exp. 7.

12 El primer contingente de inmigrantes instalados en Triscornia, en junio de 1921, se elevó a 114. Tras su llegada al campamento se les entregó una toalla y jabón, y una vez terminado el aseo, les fue servida la comida. Informe remitido desde el Consulado español de La Habana, el 20 de junio de 1921, AGAAH, AE, caja 1694; "Dietario del Consulado de España", La Lucha, 16 de junio, La Habana, 1921, AMAE, R. 748, exp. 7 . 
La Cámara de Comercio Española de Cuba tanıbién colaboró en estas circunstancias y puso a disposición del Consulado español de La Habana todos sus locales, así como su personal, para agilizar los trámites de repatriaciones, además de gestionar el cobro de los vales acreditativos de los jornales de los trabajadores que no habían podido ser pagados y que, para mayor seguridad, estaban depositados allí. ${ }^{13}$

Junto a las sociedades de beneficencia, Consulado y Cámara de Comercio, otras instituciones ayudaron a la repatriación, tales como el comité formado por el presidente del Casino Español y el delegado en La Habana de la Asamblea Suprema de la Cruz Roja; el Diario de la Marina, a través de suscripciones abiertas por todo el país, y muchos particulares dueños de fondas que dieron comida gratuita en sus locales. ${ }^{14}$

La situación se agravó tras la suspensión de créditos para pagar los pasajes a los indigentes, por lo cual los directivos de varias sociedades de beneficencia españolas se dirigieron al ministro de Estado de España en 1922 en demanda de nuevos créditos:

Los inmigrantes. . . ahora, no sólo carecerán de hogar. . . , sino también de alimentos, de ropa y de calzado. Quizás algunos de ellos, hombres útiles a la sociedad y a su familia, desesperados, delinquirán, para lograr así un sustento que honradamente no pueden obtener. Y es factible que se dé el caso de que alguno fallezca de inanición.

Con el objeto de evitar todo esto suplicamos a V.E. que, con la urgencia que las circunstancias requieren, se digne revocar la orden que ha dado motivo a este escrito, y en su lugar disponer cuanto sea conducente para que no se realicen los males que dejamos señalados. ${ }^{15}$

La situación vivida por parte de la colectividad española tras el crack bancario de 1921 es recordada de la manera siguiente por uno de los entrevistados:

El emigrante español vivía muy mal, al extremo que de aquí llegaban barcos llenos de repatriados, arruinadiños, enfermos, tuberculosos, por

13 Las gestiones comenzaron a realizarse en julio de 1921 , tras ser ello aprobado en su junta, el 15 de julio de 1921. La liquidación de los créditos concluyó el 3 de noviembre de 1922. Informe remitido por el presidente de la Cámara de Comercio Española, Industria y Navegación de Cuba, La Habana, 20 de junio de-1925, AGAAH, AE, caja 1694.

is Informe remitido por el Consulado de España en La Habana, el 20 de julio de 1921, AGAAH, AE, caja 1694.

15 La carta estaba firmada por los presidentes de la Sociedad de Beneficencia de Naturales de Cataluña, Sociedad Montañesa de Beneficencia, Sociedad de Beneficencia Gallega, Asociación Vasco Navarra de Beneficencia, Sociedad de Beneficencia Asturiana, Centro Balear, Sociedad de Beneficencia Castellana, Sociedad de Beneficencia Regional Valenciana y Beneficencia Burgalesa, La Habana, 26 de junio de 1922, AGAAH, AE, caja 1697. Por otra parte, ante esta medida, el cónsul español en La Habana se vio en la necesidad de solicitar al ministro de Estado de España, la autorización para repatriar a 250 personas por mes al menos durante junio, julio y agosto (estos meses corresponden a la época denominada tiempo muerto), cantidad que en los meses siguientes se reduciría a la mitad. Informe remitido por el cónsul de España en La Habana, el 20 de junio de 1922, AGAAH, AE, caja 1697. La medida tomada por el gobierno español fue criticada por algunos órganos de prensa de las sociedades españolas. "Los emigrantes españoles", Galicia, 11 de junio de 1921, año XX, núm. 25. La Habana. 
la situación económica del pais. Porque la quiebra de los bancos en el año veintiuno fue una combinación de la banca americana. Porque la banca cubana y española fracasaron aportando el dinero que se daba para la zafra de todos los años. Entonces quedó el país completamente paralizado, nada, nada tenía valor. ${ }^{16}$

A comienzos de julio de 1922, el paro en las minas y los trabajos del campo aumentó el número de españoles que solicitaban su repatriación, y de nuevo los presidentes de las sociedades de beneficencia solicitan al gobierno español que se haga cargo de tales demandas, ya que el disponible para este objetivo se había agotado. ${ }^{17}$

Estas demandas llegaron hasta el gobierno español que, en julio de 1923, concedió un crédito extraordinario de 1418985 pesetas destinado a los gastos de repatriación de los españoles indigentes de Cuba y los Estados Unidos. ${ }^{18}$

Por su parte, las compañías navieras accedieron en julio de 1921, tras algunas conversaciones, a rebajar el precio del pasaje. La primera en hacerlo fue la Compañía Transatlántica, la cual, a instancias del gobierno español, acordó poner a disposición del Consulado de España en La Habana la mitad de sus barcos para repatriar inmigrantes a mitad de precio, el cual se redujo de $\$ 113$ o $\$ 103.60$, en los vapores mixtos, a $\$ 73.60$. El ejemplo fue seguido por otras compañías de navegación y a partir de junio fue posible el embarque de indigentes a precios reducidos que oscilaban entre $\$ 52$ y $\$ 66.60 . .^{19}$

La crisis económica y la situación de indigencia de muchos jornaleros españoles continuó en los años posteriores. Prueba de ello son las cartas de éstos en demanda de ser repatriados, elevadas tanto a las autoridades españolas en Cuba como al gobierno español, y de forma directa a Primo de Rivera. ${ }^{20}$

Esta primera depresión económica sólo fue el antecedente y el inicio de una época de crisis, con periodos de altas y bajas, que algunos autores como Le Riverend y Ramiro Guerra extienden hasta los años cincuenta, si bien en ella hay dos momentos clave: el crack bancario de 1920 (a pesar del cual durante 1920-1924 se aprecia un aumento de la producción azucarera, acompañada de fuertes inversiones de capital norteamericano) y el periodo comprendido entre 1925 y 1933, que se inicia con una sobreproducción de azúcar y el descenso de los precios, y que coincide con la crisis mundial de $1929 . .^{21}$

16 Entrevista núm. 264, La Coruña, agosto de 1983.

17 Instancia de los presidentes de las sociedades de beneficencia españolas de Cuba, La Habana, 4 de julio de 1922, AMAE, serie Correspondencia Consulados, $\mathrm{H}$. 1432, 1921-1930.

18 En el bando dictado en Orense, el 10 de julio de 1923, el gobernador civil, Esteban Panzano Llamas, explicaba la difícil situación económica existente en Cuba y Estados Unidos y las consecuencias que ello había reportado a los trabajadores españoles allí asentados, con el fin de orientar hacia otros países el cauce migratorio AGAAH, AE, caja 1697.

I9 Informe remitido desde el Consulado de España en La Habana, el 20 de julio de 1921, AGAAH, AE, caja 1694.

20 Carta remitida desde La Habana, el 24 de abril de 1925, AMAE, Serie Política, H. 2353, $1921-1929$.

21 Ramiro Guerra, op. cit., Julio Le Riverend, Historia económica de Cuba, La Habana, Instituto Cubano del Libro, 1967. 


\section{La crisis del 29 y los años 30}

La crisis mundial del 29 se superpuso a la delicada situación económica por la que atravesaba Cuba. Los diferentes planes económicos ideados a partir de 1925 , como el de 1927 por el cual se redujo la producción azucarera, o el de 1929 por el que se volvió a la zafra libre, no obtuvieron los fines deseados. Es más: porque fue a partir de ese momento cuando Estados Unidos inició una política proteccionista por la que se gravó con fuertes aranceles el azúcar cubano, a través de la tarifa Hawley-Smoot de 1930.22

La crisis afectó al conjunto total de la economía cubana, y junto al descenso vertiginoso de la producción azucarera y de sus precios de venta, en los años siguientes a $1929,{ }^{23}$ se produjo la caída de las exportaciones de tabaco, las cuales descendieron de $\$ 41000000$ en 1927 a $\$ 13000000$ en 1933.24

Esta caída vertiginosa de los precios de las exportaciones cubanas de azúcar y tabaco, empeoraron las condiciones de vida del trabajador, que se vio obligado a trabajar todo el día y parte de la noche para ganar entre 30 y 40 centavos, ya que "el corte de caña valía hasta 10 centavos el ciento de arrobas". Pero dejemos la palabra a uno de nuestros entrevistados:

Aproximadamente, me levantaba temprano, entre las cinco o las seis, era de madrugada, me levantaba y ordeñaba y después me iba al campo a limpiar la caña y otros trabajos, y a sembrar yuca, boniatos, viandas que llaman allí. Luego después me iba a atender a otros trabajos hasta que no se mirase, hasta que no se veía. ${ }^{25}$

Muchos de los testimonios recogidos resaltan el malestar social y económico existente en este periodo, durante el cual, en muchas ocasiones, se trabajaba tan sólo a cambio de la comida. Otro de nuestros entrevistados nos dice así: ,.

Pudiera decirse que se trabajaba por la comida... Los tiempos que se trabajó por la comida fue del 28 al 34 . La gente andaba pór los caminos y no conseguía un día de trabajo por ningún precio. La cớmida en el campo estaba abundante pero no valía nada, no había dinero. ${ }^{26}$

Los planes aprobados para subsanar la depresión no hicieron sino agravar la situación de la población, que veía cómo su nivel de vida iba descendiendo. Así, tras la aprobación del Plan Chadbourne

22 Ibidem.

${ }^{23}$ Según Ramiro Guerra, op. cit., p. 229, la producción azucarera (toneladas de 2240 libras) y su precio de venta entre 1929 y 1933 fue el siguiente:

$\begin{array}{lllll}1929 & 5156278 \text { ton } & \$ 1.72 \text { la libra } \\ 1930 & 4670973 " & 1.23 & " 1 \\ 1931 & 8 & 120796 " & 1.12 & " \\ 1932 & 2604292 \text { " } & 0.72 & " \\ 1933 & 1994236 " & 0.97 & \end{array}$

24 Fabio Grobart, "El movimiento obrero cubano de 1925 a 1939", Cuba Socialista, año VI, núm. 60, agosto, La Habana, 1966, p. 88-112.

25 Entrevista núm. 229, Redondela, Pontevedra, julio de 1983.

26 Carta remitida desde Jatibonico, Sancti Spiritus, Cuba, octubre de 1984. 
por el Congreso en 1930 (por el cual Cuba reducía la exportación de azúcar y al que, por otra parte, no se acogieron otros países que mantuvieron y aumentaron su producción), el gobierno cubano, para poder cubrir los gastos presupuestarios y nivelar el presupuesto, llevó hasta el Congreso la Ley de Emergencia Económica, aprobada en 1931, que gravaba con nuevos impuestos diferentes actividades y productos de consumo. ${ }^{27}$

Diferentes periódicos cubanos y españoles criticaron la adopción de tales medidas y denunciaron la situación de indigencia en la que se sumía parte de la población. En uno de los artículos publicados en España Republicana, en septiembre de 1931, se hacía un llamamiento a la solidaridad con aquellos españoles que tenían que dormir en la calle, cuyo número ascendía a millares. ${ }^{28}$ En otras partes de la República, como en Oriente, las autoridades cubanas tomaron cartas en el asunto y pidieron a las compañías navieras la mayor rebaja posible de los pasajes a fin de lograr la vuelta a España de los miles de españoles que se encontraban sin trabajo, sobre todo, cuando la zafra concluía. ${ }^{29}$

En algunas partes de Cuba, como en Cienfuegos, los jornales del campo en 1930 eran de 60 centavos, sin incluir alojamiento ni comida, mientras que el costo de la vida oscilaba, según se calculaba, entre 60 centavos en los pueblos y 40 centavos en el campo; asimismo en algunos distritos, como Santa Clara o en las provincias de Camagüey y Oriente, los jornaleros llegaron a trabajar sólo a cambio de la comida. La situación no era menos difícil para aquellos que recibían un jornal -y que en muchas ocasiones se les adeudaba-, pues el costo de la vida era superior a los ingresos. ${ }^{30}$

Al igual que en el periodo anterior, los trabajadores del campo, al iniciarse la temporada del tiempo muerto, se trasladaron en forma masiva a las ciudades y, como entonces, el Consulado y los centros y asociaciones de beneficencia españoles se vieron saturados de demandas de repatriación.

La situación de los indigentes españoles, a la espera de repatriación, se trató de aliviar mediante la creación de un albergue español, de juntas de alimentación y de la llamada "Cocina Económica". Pero dejemos que uno de los testigos nos comente los hechos:

Había un campamento ahí, La Purísima. Se llamaba La Purísima, donde iban a comer todos los españoles. Aquí esto era tremendo. Aquí había gente que venía del campo y eso, $p a^{\prime}$ repatriarse, iban al Consulado Español. Tremendo fue eso. Gente que venía del campo. Aquí había mucha inmigración en esa época y mucha gente se tuvieron que ir. ${ }^{31}$

27 Informes enviados desde la Embajada de España en La Habana, el 15 de octubre de 1930 y el 4 de febrero de 1931, AMAE, Serie Política, H. 2353, 1921-1929.

${ }^{28}$ España Republicana, año 2, núm. 21, 30 de septiembre, La Habana, 1931, p. 1: Política Cómica, año XXV, núms. 1264 y 1265, 9 y 16 de marzo, La Habana, 1930; El País, año IX, núm. 158, lunes, 3 de agosto, La Habana, 1931; Acción Socialista, año $\mathrm{X}$, núm. 272, 8 de noviembre, La Habana, 1932, p. 3-7.

29 El País, año IX, núm. 103, martes, 9 de junio, La Habana, 1931.

${ }^{30}$ Memoria sobre emigración correspondiente al año 1930, La Habana, Imprenta Pérez Sierra y Cía., 1931, p. 4-6.

31 Entrevista núm. 328, Casablanca, La Habana, noviembre de 1983. 
Los comedores instalados a cargo de los consulados españoles y conocidos con el nombre de Cocina Económica, fueron abiertos en diferentes ciudades de Cuba, y aunque su objeto era dar de comer sólo a los españoles indigentes, a ellos se acogieron también muchos cubanos. En la ciudad de Santiago de Cuba, la Cocina Económica recibía una media diaria de mil personas, con un sustento de $\$ 120$ diarios que tuvo que reducir a $\$ 80$ por haberse agotado los fondos que dicho Consulado contaba para el mantenimiento y las repatriaciones de necesitados. El elevado presupuesto que requería la Cocina Económica provocó el cierre de la misma durante la visita del secretario de la Embajada de España, señor Forns, a esta localidad, quien, tras las conversaciones mantenidas con las autoridades militares cubanas, llegó al acuerdo de que fuera el ejército el que suministrase alimento a los indigentes españoles, lo cual resultaría menos costoso al gobierno español: la alimentación diaria de cada individuo vendría a ser de 15 centavos. $^{32}$

En la otra localidad visitada por el secretario de la Embajada, Camagüey, 1119 personas asistían diariamente a la Cocina Económica, todos españoles indigentes, ya que este Consulado había provisto a cada indigente español con un carnet de identificación. Junto a la Cocina Económica, el Consulado español en Camagüey había alquilado dos locales para el alojamiento nocturno de 600 indigentes. La escasez de fondos repercutió en la dieta alimenticia, la cual se redujo en cantidad y también disminuyó su calidad; asimismo se ordenó que cesasen las repatriaciones y que se ampliasen socorros a nuevos indigentes. ${ }^{33}$

La demanda desbordó una vez más las posibilidades y los recursos con que contaba el Consulado y muchos inmigrantes optaron por la solución de subirse al barco como polizones, ${ }^{34}$ mientras que otros recurrieron al gobierno español y al propio presidente de la República, mediante cartas en las que suplicaban por la repatriación de ellos y de sus familiares. ${ }^{35}$

Las repatriaciones realizadas hasta 1930 por las compañías de navegación españolas y extranjeras, a partir de esa fecha pasaron a ser de competencia exclusiva de las compañías navieras españolas, tras la proposición presentada y aprobada por los representantes de los centros regionales y los vocales de la extinguida Junta Consular de Emigración; reunidos en junta el 16 de octubre de 1930, en La Habana, en un intento de cortar los negocios lucrativos que se habían originado como consecuencia de la situación existente, y por estimar que los fondos utilizados para la repatriación debían de ir a parar a los fondos del erario español, ${ }^{36}$ así lo decidieron.

Para agilizar las repatriaciones, el gobierno cubano encargó la creación del Comité de Auxilio Pro Inmigrantes Españoles, consti-

32 Informe presentado por el secretario de la Embajada de España en La Habana, Sr. Forns, sobre la situación de los indigentes de Santiago de Cuba y Camagüey, en ocasión del viaje que realizó a ambas ciudades del 1 al 7 de octubre de 1931, La Habana, 10 de octubre de 1931, AMAE, R. 944, exp. 47.

33 Ibidem.

34 Informe remitido desde la Embajada de España en La Habana, el 16 de abril de 1930, AMAE, R. 453, exp. 74.

${ }^{35}$ Cartas remitidas desde Camagüey, el 9 de octubre de 1935 y desde Zamora, el 2 de junio de 1935, AMAE, R. 506, exp. 1 .

${ }^{36}$ Memoria sobre emigración correspondiente al año 1930, op. cit., p. 9-10. 
tuiido en La Habana en $1931,{ }^{37}$ el cual elevó una solicitud al gobierno republicano español a fin de que actuara como intermediario ante la Compañía Transatlántica para lograr la rebaja de los pasajes de tercera clase hasta $\$ 40$, y que fueran aprobados nuevos créditos destinados a las repatriaciones. ${ }^{38}$ Similares propuestas fueron hechas por otras sociedades como la Asociación de Dependientes de Comercio, en cuya carta, dirigida al ministro de Trabajo de España, proponía además la concesión de cien pasajes gratuitos al Consulado General de España en La Habana, mientras durase la crisis. ${ }^{39}$

Los dos organismos encargados de tramitar las repatriaciones fueron la Junta Consular de Emigración y el Comité de Auxilio Pro Inmigrante Español. Este último desde mayo de 1931 hasta diciembre del mismo año empleó sus fondos en las actividades siguientes:

\begin{tabular}{|c|c|}
\hline Costos de pasajes & $\$ 92586.81$ \\
\hline Secretaría & 2270.86 \\
\hline Mercado La Purísima & $\$ 30164.19$ \\
\hline Triscornia & $\$ 13471.75$ \\
\hline Fondas & $\$ 7007.80$ \\
\hline $\begin{array}{l}\text { Sanatorios de centros } \\
\text { regionales }\end{array}$ & $\$ 3$ \\
\hline Tot & $15^{40}$ \\
\hline
\end{tabular}

Como en el periodo anterior las sociedades de beneficencia españolas colaboraron en esta actividad. Como ejemplo de ello podemos citar el aporte de $\$ 1000$ dado por la Sociedad de Beneficencia de Naturales de Cataluña al Comité de Auxilio Pro Inmigrante Español, desde 1931 a 1932, a la vez que con sus propios fondos repatrió a 225 personas; la Sociedad de Beneficencia de Naturales de Galicia contribuyó al mencionado Comité a lo largo de 1931 , con $\$ 4000$, al mismo tiempo que destinó $\$ 1000$ mensuales para socorros. ${ }^{41}$

La gestión de los fondos destinados a la repatriación suscitó algunos problemas entre el Comité de Auxilio, los centros y beneficencias españolas y el Consulado español, el cual, en 1931, había actuado como aval de éstos ante las casas consignatarias, sin que el dinero le fuera reembolsado dentro de los plazos fijados. A raíz de esto, el Consulado de España denunció a varios dirigentes de sociedades españolas de haber cometido abusos e irregularidades en el manejo de los fondos destinados a repatriaciones. ${ }^{42}$

37 El Comité de Auxilio Pro Inmigrantes Españoles quedó integrado por el presidente del Casino Español, quien fue designado presidente del Comité; un tesorero, nombrado por la Federación de Sociedades de Beneficencia; y un secretario general. Memoria de la Sociedad de Beneficencia de Naturales de Cataluña, La Habana, 1932.

38 Memoria del Casino Español de La Habana, La Habana, Imprenta La Habanera, 1931; Diario Español, año XXIV, núm. 105, martes, 21 de marzo, La Habana, 1931, p. 3.

39 Diario de la Marina, año IC, viemes, 17 de abril, La Habana, 1931, p. 11.

40 Informe remitido desde la Embajada de España en La Habana, 1931, AMAE, R. 944, exp. 7 .

11 Informe procedente de la Embajada de España en La Habana, AMAE, R. 944, exp. 7 .

12 Memoria de la Sociedad de Beneficencia de Naturales de Cataluña, op. cit.; Diario de la Marina, 7, 8 y 9 de noviembre y 19 de diciembre, La Habana, 1931; El País, 22, 24 y 26 de septiembre y 19 de diciembre, La Habana, 1931; Información, 7 de noviembre, La Habana, 1931, AMAE, R. 944, exp. 7. 
Por otra parte, los directivos de las asociaciones españolas presionaron al gobierno español para que adoptase otras medidas que mitigaran la situación, y no sólo las de carácter económico, algunas de las cuales ya habían sido tomadas con anterioridad. Así, en una carta remitida en 1935 por los presidentes del Centro Gallego y el Centro Asturiano de La Habana, en representación de los demás, los firmantes solicitaban la aplicación de algunas disposiciones transitorias prohibiendo la emigración a Cuba, lo cual ya había sido reglamentado en la legislación española en septiembre de 1930.43

\section{La Ley de Nacionalización del Trabajo}

El panorama de desempleo que ofrecía Cuba a comienzos de los años treinta, se vio aumentado, en lo que respecta a la colectividad española, a partir de la promulgación de la Ley de Nacionalización del Trabajo o Ley del 50\%, Decreto Núm. 2232, de 18 de octubre de 1933, por la que se exigía ocupar un porcentaje mínimo de $50 \%$ de trabajadores nativos en cada una de las empresas, industrias, comercios. .., etc. En el mismo decreto, Grau San Martín autorizaba la repatriación forzosa de los extranjeros sin trabajo y sin ningún tipo de recursos. ${ }^{44}$

Como antecedente de esta ley, ya en 1925 Lombard había presentado a la Cámara de Representantes el Proyecto de Ley del $75 \%$ que fue aprobado por dicha Cámara el 10 de noviembre de 1925 . Esta ley obligaba a toda persona natural o jurídica que tuviera una industria o comercio en Cuba, en la que trabajasen más de cinco personas, a contar entre sus trabajadores con $75 \%$ como minimo de empleados de nacionalidad cubana. ${ }^{45}$ Dicha ley no fue llevada a la práctica durante el gobierno de Machado y Morales, quien pese a la protesta del gobierno español, no le dio cumplimiento. ${ }^{46}$

La aplicación de esta ley no se hizo efectiva hasta la caída del general Machado, a instancias del gobierno presidido por Ramón Grau San Martin en 1933.

Las repercusiones de dicha ley en el seno de la colectividad española son fáciles de imaginar. Por una parte, muchos se vieron obligados a pedir la repatriación forzosa, sobre todos aquellos que trabajaban fuera del sistema organizado por el grupo español, dentro

43 AMAE, R. 943, exp. 51: Gaceta de Madrid, 26: y 27 de septiembre de 1930.

44 Lionel Soto, La revolución del 33, La Habana, Editorial de Ciencias Sociales, 1977, t. 3, p. 198-202.

45 Informe remitido por el cónsul de España en Santiago de Cuba, el 16 de noviembre de 1925. AGAAH, AE, caja 1694; Diario de la Marina, edición de la mañana, 12 de noviembre, La Habana, 1925.

46 Informe remitido desde la Legación Española de La Habana, enero de 1926, AMAE, Serie Política 2352, 1921-1929. Tras ser conocido el proyecto de Lombard, algunas sociedades se dirigieron al presidente Machado para que meditase sobre las repercusiones negativas que tal ley reportaría a la colectividaut española de Cuba. Con este fin, el alcalde de La Coruña, a través del presidente del Centro Gallego de La Habana, se dirigió a Machado en una carta publicada en el Diario de la Marina, año XCIV, jueves, 7 de enero, La Habana, 1926, p. 30. Esta via mbién fue utilizada por la Cámara de Comercio de Remedios, la cual consideraba anticonstitucional la Ley del 75\%. Diario de la marina, año XCIV, núm. 10, 10 de enero, La Habana, 1926, p. 3. 
del cual se idearon las trampas por las que aquellos que no se hicieron ciudadanos cubanos, pasaron a ser miembros asociados del negocio donde trabajaban; de tal manera, como socios-propietarios, quedaban fuera de lo dispuesto por la ley. Por otra parte, a partir de ese momento el porcentaje de españoles que adoptaron la ciudadanía cubana se incrementó considerablemente, y aun aquellos que eran dueños de negocios se decidieron por ello ante las dificultades crecientes que como extranjeros tenían. ${ }^{47}$ Nuestros entrevistados, unos a favor y otros en contra, dan constancia de ello en sus relatos:

A los españoles les dejaron sin trabajo. Que por cierto, tuvieron que venir barcos aquí a recoger gente que estaba tirada, familias enteras y los llevaron pá España... 48

Antes no tenía problemas para el trabajo, podía colocarme donde quisiera. Pero después, cuando vino la cosa grave, había que hacerse ciudadano cubano. Si no, no podias trabajar nada, tenías que andar escondido. . . Se corría la voz de que iban a poner un tributo muy grande al extranjero aquí. . . Y la molestia de estar sacando todos los años ese carnet. . Y Yo me hice ciudadano cubano. ${ }^{19}$

Todos los informes, telegramas y cartas procedentes de Cuba en este periodo se centran en la difícil situación creada para el inmigrante español, ya que si bien unos debían de abandonar Cuba o nacionalizarse cubanos; otros vieron afectados sus intereses al ser atacados algunos de sus establecimientos por nativos, por lo que reconsideraron su situación en la isla, e iniciaron gestiones ante los consulados a fin de saber si el gobierno español les daría plenas garantías en el caso de que trasladasen sus negocios a España..$^{50}$

La promulgación de la Ley del $50 \%$, fue mal acogida entre la colectividad española, en especial por el Sindicato de Empleados del Comercio, integrado por muchos españoles; algunos sectores quisieron reformarla, pues consideraban que su aplicación en general a todo extranjero era injusta. ${ }^{51}$ Así, el Club de Cantineros presentó al Congreso Nacional Obrero, celebrado en La Habana en noviembre de 1937, una propuesta para que no se considerasen extranjeros a todos aquellos inmigrantes casados con nativos, que hubieran formado una familia, y que llevaran diez años de residencia

47 Los extranjeros que no adoptaron la nacionalidad cubana quedaron obligados a partir de 1933 a inscribirse como tales en el Registro de Extranjeros, además de tener que poseer un carnet de extranjero, el cual debían de renovar todos los años. Gaceta Oficial, año XXXI, núm. 137, martes, 12 de diciembre de 1933. La Habana, 1933, tomo IV, p. 8171-8174.

El Decreto de extranjeria estipulaba el pago de $\$ 5$ anuales a los propietarios, industriales, profesionales y comerciantes extranjeros que devengasen un sueldo superior a los $\$ 600$ anuales y de $\$ 1.45$ para aquellos cuyas ganancias fueran inferiores a tal cantidad.

48 Entrevista núm. 310, La Habana, octubre de 1983.

49 Entrevista núm. 325, La Habana, octubre de 1983.

50 Telegramas cifrados desde la Embajada de España en La Habana, el 3 y el 10 de enero de 1934, AMAE, Sección de Ultramar, R. 840, exp. 13.

${ }^{51}$ Despacho remitido por el Embajador de España en Cuba, López Ferrer, La Habana, 31 de diciembre de 1933, AMAE, Serie Política, R. 698, exp. 16. En 1934 comenzaron a correr rumores sobre un proyecto de ley que regularia la devolución del dinero que los españoles hubieran aportado a los fondos de las cajas de jubilación. Informe enviado por López Ferrer, La Habana, agosto de 1934, AMAE, R. 325, exp. 1 . 
en la isla. ${ }^{52}$ Asimismo, la Lonja de Comercio elevó una protesta al presidente cubano en la que pedía la suspensión de dicha ley o bien se facilitasen los trámites de nacionalización para aquellos extranjeros que llevasen cinco años en Cuba y tuvieran familia cubana. ${ }^{53}$ Por otra parte, se constituyó la Comisión de Pro Residentes Españoles de Pre 1933 con el objeto de que influyera en la opinión pública y de que presionase al gobierno cubano para que fuese considerado residente en Cuba todo aquel español llegado a la isla antes de 1933, con el fin de que tuviera derecho a trabajar libremente. ${ }^{54}$

Con el mismo objetivo que los anteriores, un grupo de españo. les antiguos residentes en Cuba se dirigieron a la Asamblea Constituyente el 1 de marzo de 1940, en vísperas de la elaboración de la Constitución de 1940, a fin de que en ésta se rectificase la ley promulgada en 1933, la cual consideraban debería ser del $100 \%$. En la carta los firmantes se referían a la labor desempeñada por los españoles en Cuba, como generadores de riqueza y a éstos como parte del país, donde la mayoría residía desde hacía tiempo y donde habían formado una familia. ${ }^{55}$

Como respuesta a estas actitudes, el periódico La Voz Obrera publicó en diferentes ocasiones artículos en défensa de la Ley del $50 \%$, por la protección que ésta concedía a los trabajadores nativos, y la cual estaba exenta de carácter xenófobo alguno. ${ }^{56}$

Tras la promulgación de esta ley, el gobierno cubano autorizó la repatriación forzosa de los extranjeros sin ocupación y sin recursos. En el Decreto Núm. 2232, de 18 de octubre de 1933, se estableció que el estado correría a cargo de los gastos de repatriación, así como la entrega a cada repatriado de $\$ 200$, medidas que fueron abolidas por el Decreto Núm. 3130, de 14 de diciembre de 1933 .

Ante el empeoramiento de las condiciones de vida se creó en La Habana un Albergue Español en 1934, con fondos procedentes de la colectividad española y del Consulado de España. Para su instalación el cónsul pidió la concesión de un crédito de $\$ 250$, y la partida de $\$ 150$ mensuales para su mantenimiento. ${ }^{57}$

En esta época se multiplicaron las peticiones de nuevos créditós destinados a auxilios y repatriaciones, y en todas ellas se hacia constar el carácter apremiante de las mismas. Un ejemplo de ello to constituye el informe de la Embajada de España en La Habana, de agosto de 1934, en el que se solicitaba la concesión de un crédito extraordinario al haberse agotado el fondo de $\$ 8000$ para socorros y

32 Memoria del Club de Canlineros, La Habana, 1951, p. 371.

s3 Problemas de la nueva Cuba, op. cit.

s4 Hoy, año III, núm. 69, 20 de marzo, La Habana, 1940, p. 7.

35 Pueblo, lunes, 18 de marzo, La Habana, 1940. La Constitución de 1940 consideraba ciudadanos cubanos por naturalización: Los extranjeros que después de cinco años de permanecer en Cuba, y no menos de uno después de haber declarado su intención de adquirir la nacionalidad cubana, obengan la carta de ciudadania con arreglo a la ley, siempre que conozcan el idioma español. Los extranjeros casados con nativos que tuvieran hijos o llevasen dos años en Cuba tras su matrimonio. (Art. 130. Título Segundo de la Ley de Nacionalización.) Manuel Martí Escalena, Legislación obreta, 1941.

s6 La Voz Obrera, año XI, núm. 450, 25 de diciembre, Santiago de Cuba, 1933; año XII, núm. 473, 25 de noviembre, Santiago de Cuba, 1935.

37 Despachos remitidos por el cónsul de España en La Habana, el 19 de enero y 17 de febrero de 1934, AMAE, R. 353, exp. 83. Véanse también los periódicos $A$ hora, $15,18,29$ y 31 de enero y 1 de febrero. La Habana, 1934; y El País, 27 de enero, La Habana 1934, AMAE, R. 9.51, exp. 3. 
repatriaciones. Ante la urgencia del caso, se concedió un crédito de 168000 francos, el cual fue depositado el 26 de agosto en el Banco de España. ${ }^{58}$

Otras medidas similares fueron adoptadas a lo largo de estos años, entre ellas cabe citar el acuerdo firmado por el Estado español y la Compañía Trasatlántica, en 1934, por el cual dicha compañía redujo en un $50 \%$ el coste del pasaje. Además de ello, el gobierno, previo aviso con 15 días de antelación, podía disponer de la cuarta parte de las plazas destinadas a bordo de los buques para pasajeros, y de la tercera parte para el transporte de los indigentes que se hallasen bajo el amparo de él. ${ }^{59}$

De forma particular algunas asociaciones e individuos se dirigieron al presidente de la República española pidiendo la repatriación.

\section{Actividades económicas del español}

La realidad encontrada en Cuba en el periodo estudiado chocaba con los sueños de todos los jóvenes que veían en América la tierra de Jauja, donde el trabajo sería mucho más liviano que el dejado atrás y donde pronto les sonreiría la fortuna. Los relatos de todos los emigrantes no dejan de apuntar todas las "fatigas" que, al menos durante algunos años desde su llegada, tuvieron que pasar, así como la explotación a la que se vieron sometidos por sus propios paisanos. Estas experiencias que hemos recogido a lo largo del trabajo del campo son el núcleo básico de información que poseemos para acercarnos al vivir cotidiano de los hombres y mujeres que un día decidieron mejorar su vida y marchar a "hacer la América".

Las historias de vida se repiten una y otra vez y en todas ellas sus protagonistas enfatizan y reiteran, como por temor a que nos perdamos en sus relatos, todos los trabajos pasados hasta que llegaron a situarse. Unos como intentando justificar y a la vez resaltar la posición lograda, otros tan solo con el empeño de dar a conocer su vida, que hasta el momento de la entrevista creían sin importancia, pero todos ellos vertiendo en ti una confianza y por ello causándonos la obligación de narrar, como decían, "mejor con tus palabras lo aquí vivido". Pero nadie mejor que ellos pueden dar luz a este apartado de la investigación, el cual les pertenece en su totalidad.

\section{El bodeguero}

El trabajo en la tienda de comestibles, de ultramarinos, que también podía tener una cantina, estuvo monopolizado por el inmigrante español. Aunque éste también se ubicó en otros sectores laborales en el medio urbano, como ya hemos estudiado, la bodega fue no sólo el principal medio de subsistencia sino también el que ha prevalecido en la mentalidad del pueblo cubano, hasta el punto

58 Despacho enviado por el cónsul general español, La Habana, 30 de agosto de 1931, AMAE, R. 353, exp. 82

59. Carta firmada en Madrid, el 7 de agosto de 1934, remitida al cónsul de la nación en Veracruz, AMAE, $R$. 508 , exp. I4. En abril de 1934 la Trasatlántica había ofrecido un cupo de treinta pasajes, a \$37.80, al menos hasta finalizar el año. Esta medida fue seguida por otras compañías como la Pacific Steam Navegation Company que estableció el mismo cupo y precio. Inlome enviado por el cónsul de España, La Habana, 13 de abril de 1934, AMAE, R. 504, exp. 2. 
de igualar al inmigrante español, al "gallego", con el bodeguero. Es por ello que hemos elegido este trabajo para reflejar el vivir cotidiano de un gran sector de la colectividad española.

La bodega en realidad era la tienda donde uno podía abastecerse de casi todo, desde los víveres y las bebidas, hasta el calzado y los sombreros: "Lo que quisiera usted lo encontraba allí, un alfiler, una zapatilla, un centavo de sal, un bote de pintura. . ." Un espacio reducido que a la vez servía al dueño y a sus empleados de vivienda, y donde los entrevistados pasaron gran parte de su juventud.

La sonrisa de los relatores ante mi pregunta sobre la jornada laboral era explicativa por sí misma: "Bueno, la jornada de ocho horas yo nunca la pude coger. ¿Sabe por qué? Porque era en la bodega y no había jornada". ${ }^{60}$

La jornada laboral comenzaba de madrugada y se prolongaba durante todo el día hasta altas horas de la noche, con un promedio de 15 horas diarias, sobre todo en aquellas que tenían cantina:

A las ocho cerrábamos la parte de ultramarinos y seguíamos vendiendo en la cantina... La cantina la cerrábamos sobre la una de la madrugada y me levantaba sobre las siete. . Dormíamos dentro de la bodega, allí teníamos unos catres que se cerraban, se ponian detrás de la puerta y se ponían entre la mercancía... Por las mañanas iba con una lista casa por casa de los clientes a ver lo que querían y se les servía en casa, yo caminaba mucho y en zapatillas de esparto, y me enfermé y dije, venderé periódicos antes de volver a una bodega. ${ }^{61}$

La legislación trató en diferentes ocasiones de poner fin a tales abusos. En 1910, el 4 de mayo, se dictó una ley nacional, Ley de cierre o Ley de periodo laboral y descanso dominical, por la cual todos los establecimientos de comercio y talleres situados en los barrios urbanos de los municipios de primera y segunda clase deberían cerrar a las 6 de la tarde, de lunes a viernes y a las 8 p.m. los sábados, a la vez que establecía la prohibición de trabajar los domingos y festivos. Por lo que respecta a las tiendas de ultramarinos, éstas debían cerrar a las 8 p.m. los días de semana y a las 10 de la mañana los domingos (Art. $1^{0}$ ). ${ }^{62}$ Pese a ello, los trabajadores continuaron cumpliendo largas jornadas, más aún si tenemos en cuenta la oposición de los dueños de establecimientos comerciales al cumplimiento de esta ley, que iba contra sus intereses económicos, "ya que no sería beneficioso albergar a los dependientes en el comercio".63

La ley de 20 de julio de 1933 volvió a marcar la jornada laboral de 8 horas para los establecimientos comerciales, excepto para las bodegas. Los primeros dividirían su jornada de 8 de la mañana a 12, con dos horas de descanso para el almuerzo, y de 2 a 6 de la

* Entrevista núm. 303, La Habana, octubre de 1983.

61 Entrevista núm. 234, La Coruña, julio de 1983.

62 Quedaban fuera de esta disposición los hoteles, restaurantes, cafés, establecimientos de espectáculos públicos, kioscos de tabaco, talleres, oficinas de periódicos e industrias en las que fuera necesario un trabajo continuo. Así como las droguerias y farmacias, las cuales no tendrian una jomada superior a 10 horas (Art. 20). Legislación obrera de la Repúblice de Cuba, La Habana, Secretaría de Agricultura, Comercio y Trabajo, 1919. Véase también la obra dirigida por José $R$, A study of Cuba. Cuban Economic Research Project, Miami, University of Miami Press, 1965, p. 276.

c3 Informe remitido por la Legación de España en Cuba, La Habana, 28 de abril de 1910, AMAE, Serie Correspondencia Consulados, H. 1430, 1902-1910. 
tarde, de lunes a sábados. Para la bodega la jornada fue fijada en 10 horas, la cual comenzaba a las 7 de la mañana y terminaba a las 7 de la tarde de lunes a sábados, y de 7 de la mañana a 12 del mediodía los domingos. ${ }^{64}$ Habrá que esperar a la Constitución de 1940 , Art. 66, título sexto, sección primera, para ver igualada la jornada laboral en bodegas a la de otros establecimientos y sectores, además de establecer un mes de descanso retribuido y el reconocimiento del derecho de sindicalización a los patrones, empleados privados y obreros, Arts. 67 y 69 , respectivamente. ${ }^{65}$

Pero junto a estas leyes los propietarios de bodegas idearon las trampas. El soborno a los guardias y la entrada por la trastienda impidieron que las leyes actuasen.

Trabajábamos, se cerraba la bodega y se dejaba una puerta abierta y venían los clientes, ya sabían. Y despachaba más después de que se cerraba que antes. ${ }^{66}$

Se implantó el horario de los domingos, que entonces proyectaron cerrar una acera y trabajaba la otra. Pero no se llevó a cabo por la trastienda... que muchos aceptaban descansar y metían a gente por la trastienda. Que era una burla entre ellos mismos. ${ }^{67}$

Las duras condiciones de este trabajo hacen decir así a uno de los entrevistados:

A pesar de yo ser aldeario me gustaba la libertad y el giro de bodega era un giro muy esclavo. Había que trabajar muchas horas y todos los días, incluyendo domingos $\mathrm{y}$ todo. $\mathrm{Y}$ entonces, tan pronto como pude, me dejé el giro de bodega y me dediqué a otros giros. ${ }^{68}$

Testimonio que hace honor a la verdad si se tiene en cuenta el régimen de vida de estos hombres:

Allí los dependientes de bodega dormíamos en la trastienda en medio de patatas y cebollas medio podridas, donde había una cantidad de mosquitos que aquello era horroroso. ${ }^{69}$

Bueno, figúrese, unas camas pequeñas de hierro, a mí me dieron un catre pero ese se rompió, estaba podrido y se rompió. Entonces, yo como era muchacho no me atrevi a pedir otro y dormía en el suelo. Se dormía mejor en el suelo que en el catre. ${ }^{70}$

Este tipo de vida fue recogida por Irene Wright en su libro Cuba, del cual dedica un capítulo a los extranjeros en la isla y entre éstos menciona la figura del bodeguero:

A las 4:30 de la mañana comienzan su jornada y hasta la medianoche no cierran. . Los dependientes viven en la misma casa donde trabajan, duermen en el suelo..., esperan que aquel "viejo" se retire para quedarse al frente del negocio..., y aunque terminen su trabajo ellos no

\footnotetext{
64 Manuel Martí Escasena, Legislación Obrera, op. cit. p. 302.

65 Ibidem.

66 Entrevista núm. 249, La Coruña, julio de 1983.

67 Entrevista [s.n.], La Coruña, agosto de 1983.

68 Entrevista núm. 290, La Habana, octubre de 1983.

69 Entrevista núm. 264, La Coruña, agosto de 1983.

70 Entrevista núm. 331, La Habana, noviembre de 1983.
} 
tienen la noche libre. Se sientan en las puertas de las tiendas y juegan al dominó o van a escuelas nocturnas de los centros regionales. ${ }^{71}$

Pero el excesivo trabajo no iba acompañado de una remuneración gratificante y en muchos casos ni siquiera de un pequeño sueldo. A cambio de la comida, la "casa", el lavado de la ropa y el pago del recibo de alguna sociedad benéfica o centro regional, el joven debía trabajar en la bodega a la espera de un ascenso en su puesto de trabajo.

Entonces no ganábamos nada, le daban la comida, le daban tabaquito y su lavao de ropa y si usted pedía algo se lo daban. Con eso [se] tenía que arreglar. ${ }^{22}$

Me fui para la casa de mi tío a despachar, así me salió el pelo. Allí no gané ni un céntimo porque no me lo dio. . Entonces estuve así un año y medio. ${ }^{73}$

Esta situación se repite continuamente y en un principio el muchacho, y dependiente después, tarda algún tiempo en saber el sueldo que le correspondería. A sus preguntas sobre este particular, el bodeguero siempre tenía la respuesta oportuna: él le guardaría el dinero para que poco a poco fuese ahorrando y lograse establecerse. Pero lo cierto es que detrás de ello estaba todo un sistema de explotación que a veces se amparaba en los lazos familiares y de amistad que unían a patrón y empleado, y las ilusiones de éste por ser el heredero de la pequeña bodega cuando su patrón muriese.

Empezaban todos como aprendices y en eso incluso no les llegaban ni a pagar. . A Ahora últimamente no (años 50). Ya cobraban una cuota que tenían estipulada en un conven io entre los comerciantes y, por ejemplo, les daban quince o treinta pesos como aprendices. ${ }^{74}$

\section{El medio rural}

Se trata de nuestros compatriotas, en la creencia de que es oro todo lo que reluce, vienen animados en sus mejores deseos a esta República, donde sin contrato de ningún género, fiándose sólo de la palabra de propietarios de grandes fincas azucareras los más, y cuando más de segundas y terceras personas sin solvencia; en grandes núcleos, a veces de más de cien, se dedican al fomento de esos terrenos sin otra garantía que un simple convenio verbal, mediante el cual se les dice se les abonará cierto salario más la comida. . también se da el caso de que el dueño de la finca una vez que ve que el trabajo está terminado o casi para terminar, se vale de miles de medios para expulsarlos de su finca.

Con estas palabras, el cónsul español en Santa Clara, al igual que otros cónsules de diferentes provincias, daban testimonio de la realidad con la que el jornalero español se encontraría a su llegada al campo cubano en $1920 .{ }^{75}$

71 Irene Wright, Cuba, Nueva York, The Macmillan Company, 1910, p. 135-163.

72 Entrevista núm. 324, La Habana, octubre de 1983.

73 Entrevista núm. 282, La Coruña, septiembre de 1983.

74 Entrevista núm. 272, La Coruña, agosto de 1983.

75 Carta enviada por el cónsul español en Santa Clara al cónsul general de Es- * paña en La Habana, el 29 de noviembre de 1920, AGAAH, AE, caja 1694. 
Los canarios, llamados "isleños" por los cubanos para diferenciarlos de los inmigrantes procedentes de la península, "gallegos", fijaron su residencia en un mayor porcentaje con respecto al resto de la inmigración española en el medio rural, característica que se prolongaría desde el siglo XIX hasta el actual. Quizá el diferente sistema de emigración que observamos en estas islas puede ser una explicación de este hecho, ya que, en la emigración canaria, el sistema de paisanaje o parentesco tiene un lugar secundario. La emigración golondrina tradicional de Canarias, destinada a las tareas agrícolas durante las épocas de cosecha y zafra, ofrecía una mayor dificultad de asentamiento definitivo en la isla que para aquellos que habían sido reclamados por familiares o bien que a su llegada a la ciudad encontraban un trabajo permanente. Para el trabajador rural (no nos referimos por supuesto al que emigró de acuerdo con los planes de colonización cubanos), las posibilidades de llegar a ser el dueño, socio o interesado del central o ingenio donde trabajase eran mucho más remotas que para cualquier empleado de tienda o almacén. El capital disponible para invertir en la tierra era mucho mayor que el necesitado para la compra, con otro socio, de un pequeño negocio en la ciudad y muy pocos lograron, a través de sus ahorros, llegar a ser propietarios.

Tampoco éstos se libraron de la explotación de la que sus paisanos eran objeto en la ciudad. El trabajo agotador de sol a sol, las malas condiciones de vida, la inseguridad en el trabajo una vez terminada la época de recolección, fue la realidad con la que estos hombres se encontraron, contra la que algunos lucharon y en la que muchos vivieron toda su vida. Uno de ellos nos contaba así en su carta:

Cualquiera que tuviera uso y razón en aquel tiempo podía contar muchas cosas que pasaron, que muchos no lo recuerdan, pero el que tiene memoria no las puede olvidar; los atropellos de la policia y la guardia rural. . robaban a diestra y siniestra, botaban las familias para el camino real sin más ley que la que elios imponían, el plan de machete, y si les hacian resistencia usaban las armas de fuego. ${ }^{76}$

Pero el inmigrante no sólo tenía quehacer frente a este tipo de injusticias y bandolerismo; se tuvo que enfrentar a un medio hostil donde las épocas de escasez se hacían sentir más que en las ciudades y donde el aislamiento le hacía más indefenso.

En los sitios de tabaco, también llamados vegueríos, el trabajo se prolongaba desde noviembre a marzo, época que coincidía con la zafra, desde octubre-noviembre hasta mayo, por lo cual los obreros del campo se encontraban, durante los meses restantes llamados "tiempo muerto", sin ningún tipo de trabajo. Durante el tiempo muerto, el jornalero que permanecía en los ingenios o en los sitios de tabaco, prestaba sus servicios a cambio de la comida para poder seguir sobreviviendo hasta la cosecha siguiente. En muchos ingenios y sitios, los dueños prestaban a sus empleados. lo necesario para sobrevivir esos meses, cantidad que les era descontada del salario que habrían de percibir en la estación de trabajo.

76 Carta remitida desde Jatibonico, Sancti Spiritus, Cuba. Octubre de 1984. 
Le daban la comida, la caja de cigarrillos, en el tiempo muerto, [lo] que se lla maba el tiempo muerto, y los tenían nada más que a base de eso, y luego, si ganaban algo; era en tiempos de la zafra. ${ }^{77}$

Los que no permanecían en los centrales o vegueríos probaban mejor suerte en otros trabajos, ferrocarriles o minas, e incluso alguno se acercaba hasta La Habana para regresar después al campo: "Nosotros trabajábamos por nuestra cuenta en tiempo muerto. En La Habana se trabajaba menos pero siempre tenía que comer." 78

El trabajo a destajo también fue corriente entre nuestros entrevistados. . "El jornal, bueno eso era por cientos de arrobas. Nosotros estábamos a tasa, a tasa por cada cien arrobas. Nosotros sacábamos el dinero siempre que era buen año." 79 Pero no siempre el obrero recibía el importe de su sueldo en efectivo. Hasta 1909 el obrero recibía su salario en vales o cheques que sólo podía canjear en la tienda o bodega del ingenio que, dicho sea de paso, era también propiedad del dueño de la plantación y donde los víveres y otros productos necesarios para el jornalero estaban a precios superiores a los de las bodegas del pueblo. La Ley Arteaga, de 23 de junio de 1909, prohibía el pago de jornales con vales, fichas metálicas o de cualquier otra clase que tuvieran el carácter de signos representativos de la moneda. Su infracción sería castigada con una multa no inferior a $\$ 500$ o con arresto de seis meses; pese a lo cual, su aplicación fue lenta y volvió a repetirse en la Constitución de 1940 (Del trabajo y de la propiedad, Art. 64, título sexto), en donde se incluía una nueva cláusula por la que se fijaba que los jornaleros recibirian su salario en un plazo menor de una semana.80 "Sí, vivían. Te daban facilidades si tú no tenías el dinero, los jefes tenían tiendas en las colonias y te aaban vales y tú comprabas con los vales esos." 81

Estos hechos fueron denunciados en repetidas ocasiones por la prensa y puestos en conocimiento de las autoridades españolas acreditadas en Cuba, quienes confirman en sus informes el pago de salarios mediante vales y que llevaron a cabo las oportunas diligencias ante los tribunales para finalizar con tales abusos. ${ }^{82}$

La vivienda consistía en un bohío, una cabaña levantada por el campesino a base de hojas de palma de guano, con suelo de tierra y en las mejores ocasiones, de tabla. Sobre las condiciones de vida, alojamiento y comida, hemos elegido lo que nos cuenta en una de sus cartas un anciano campesino desde la localidad de Jatibonico, en Sancti Spiritus:

Los bohíos algunos son de tabla y guano, otros son de vara, en tierra esos no tienen tabla, es nada más que el techo de guano puesto en el suelo, eso depende del dueño si es consciente con los trabajadores o no. Por la comida es lo mismo, la comida algunos la dan mejor aunque sea lo mismo, vianda, arroz, frijoles, harina de maíz y leche, hay donde se

77 Entrevista núm. 335, Orotava, Tenerife, diciembre de 1983.

78 Enuevista núm. 299, La Habana, octubre de 1983.

79 Entrevista núm. 305, La Habana, octubre de 1983.

so Legislación obrera de la República de Cuba, 1919, op. cit., Manuel Martí Escalena, op. cit.

81 Entrevista núm. 192, Madrid, enero de 1982.

82 "El cónsul de España informa sobre las denuncias de malos tratos a inmigrantes", Santiago de Cuba, 30 de agosto de 1913. 
puede comer pero hay otras que la misma comida no se puede comer. Carne, algunos dan carne, almuerzo y comida. Otros no la dan, sea porque no pueden o porque no quieren por ahorrar más.

Algunos trabajadores consiguieron ser colonos, lo que les permitía tener arrendada una parcela de terreno donde criaban algunos animales y cultivaban viandas para el consumo propio, y tabaco o azúcar que, al final de la cosecha, vendían al propietario. Uno de ellos nos los explica de la manera siguiente: "Aquí el nombre de colonos era porque esas colonias pertenecian a los ingenios y ellas pagaban un tanto de alquiler, sembraban la caña y luego [los ingenios] se la compraban". 83

Los sitios de tabaco arrendados en parcelas eran a su vez arrendados a otros, a los "partidarios", que eran los encargados de cultivar el tabaco, los cuales recibian un salario en relación a lo producido. Ante nuestras constantes preguntas uno de los informantes nos aclara este proceso:

Un sitio de tabaco o veguerío como también se le conoce, son fincas muy grandes que se arriendan en parcelas de distintos tamaños, según las posibilidades del que las arriende y las rentas dependen de que los terrenos sean mejor o peor. . . Los sitieros o arrendatarios no se dedican personalmente al trabajo, entonces ponen cuatro, seis, ocho o más partidarios, de acuerdo con el tamaño del sitio para atender la cosecha del tabaco. . En el tabaco no hay horario o sueldo, depende de la producción, al término de la cosecha, después de sacar los costos de producción, el o los partidarios que son los que atienden el cultivo, cobran la mitad que por eso se les llama partidarios. ${ }^{84}$

\section{Ratos de ocio}

Las horas libres y los días de descanso eran aprovechados para reunirse con sus paisanos en los centros y asociaciones, donde jugaban al billar, a las cartas y cómo no, al dominó, donde tomaban algunos "tragos" y si se celebraba alguna fiesta, bailar. Aunque hay que hacer la salvedad para aquellos que estaban en el interior de la isla y la colonia española (asociación española) más próxima, les quedaba a horas de camino. Para éstos el campo de diversión era más reducido y entre sí, en los ingenios y lugares de trabajo se reunían a hablar de su tierra y a comentar lo último ocurrido.

Los centros regionales, las asociaciones benéficas y los clubes comarcales y municipales creados para amparar al emigrante, cumplieron bien su papel en lo referente a ser lugares de reunión donde el individuo siempre tenía con quien conversar o un grupo con el que jugar la partida. La visita a estos centros en la actualidad, en que los miembros de la colectividad española son personas de avanzada edad, refleja esta situación. Los españoles siguen acudiendo alli puntualmente a "echar" la partida, a dormitar en los balancines cubanos, a resolver gestiones relacionadas con la sociedad, a organizar las fiestas y veladas que siguen ofreciendo y a ser interrumpidos en sus actividades por una curiosa con un paquete interminable de preguntas.

83 Entrevista núm. 323, La Habana, octubre de 1983.

84 Carta enviada desde Jatibonico, Sancti Spiritus, septiembre de 1984. 
Bueno, nos juntábamos, íbamos al Centro Asturiano y hasta el año veinte pues pasábamos la Nochebuena en el parque central, los gallegos por un lao y los asturianos por otro. Pero donde más nos agrupábamos era en los centros. ${ }^{85}$

En estos centros el individuo encontraba a otras personas con problemas similares a los suyos, con un pasado común, con unas perspectivas semejantes y sin un entorno familiar, al menos al llegar, donde cobijarse. Pero demos paso a la palabra de uno de ellos:

Siempre uno busca el ambiente de uno. Tú eres emigrante de aquella época, pues buscas los muchachos de aquella época emigrantes, de las sociedades a que tú perteneces poco más o menos, tú comprendes, del mismo ambiente, de la misma cultura poco más o menos que tú eras, pues es lo que tú vas tratando. ${ }^{86}$

Buena parte de la vida de los inmigrantes giraba y gira alrededor de los centros y asociaciones españolas, puesto que en éstos, además de lo ya mencionado, el individuo encontraba una amplia gama de servicios, desde los hospitalarios a los culturales. Junto a las fiestas, también llamadas veladas en las que se ofrecían cenas o acudían a espectáculos organizados por las escuelas de baile de cada sociedad, se celebraban romerías que se correspondían a los días fijados en el calendario litúrgico español. Cada centro y sociedad, de tal o cual parte de España, posee su propio patrón, de acuerdo a su procedencia y como tal reproducían lo dejado atrás: "Pensar que estaban en la propia España, en su región, viviendo con alegría cuando se hacían fiestas." 87

A los que su horario se lo permitía o a aquellos que todavía les quedaba ánimo después de la jornada, acudían a las escuelas nocturnas de estos centros, unos para obtener algún título que les permitiera un ascenso más rápido y la gran mayoría para completar su educación.

Un centro cultural donde aprendían a leer y a escribir el que no sabía, matemáticas y todo daban de noche. Be día no. . ., sino después de las siete de la tarde iba la gente a aprender lo que quería. ${ }^{88}$

Suerte que algunos no pudieron aprovechar por la prolongada jornada laboral. Una de estas personas nos comenta lo siguiente:

No, no tuve, no tenía tiempo tampoco. Si trabajaba no tenía tiempo. Tenía que acostarme porque al otro día a las cinco de la mañana tenía que levantarme a trabajar. A mí me mandaron a la Quinta de Dependientes a estudiar de enfermero. $Y$ le dije al jefe de personal, "Don Andrés, ¿cómo usted cree que voy a estudiar un día sí y un día no, si estoy hasta las diez de la noche aquí? Y aquí hay que trabajar. Usted me va a regañar si esto está abandonado". ${ }^{89}$

Los periódicos constituyeron la fuente básica de lectura para el inmigrante, 'especialmente aquellos que dedicaban gran parte de sus

85 Entrevista núm. 297, La Habana, octubre de 1983.

86 Entrevista núm. 11, Miami, julio de 1981 .

87 Entrevista núm. 295, La Habana, octubre de 1983.

8s Entrevista núm. 334, Orotava, Tenerife, diciembre de 1983.

89 Entrevista núm. 289, La Habana, octubre de 1983. 
editoriales a la colonia española, cuya elaboración la llevaba a cabo un cronista destinado exclusivamente a ello, así como los que contenían noticias sobre España. Algunos periódicos cubanos, españoles y revistas o boletines de los centros y asociaciones gozaron de gran popularidad entre la colectividad española. Entre ellos tenemos que destacar al Diario de la Marina, fundado en 1844 por Ribero, asturiano, cuya dirección fue siempre propiedad familiar, de marcada tendencia conservadora, el cual durante la guerra civil española ofreció su apoyo abierto a los rebeldes y a la Falange Española y Tradicionalista de las JONS existente en Cuba. A este periódico estaban suscritos la mayoría de los comerciantes habaneros, de los cuales un elevado porcentaje eran españoles. Las causas de afiliación comentadas por nuestros informantes presentan gran interés para la investigaciọn, ya que la gran mayoría que contestaron haber leído con asiduidad tal periódico, lo justifican por ser este diario el que más defendía a los españoles, e incluso llegan a decir que "era el periódico de los españoles", y no tanto por otras razones como, por ejemplo, la información copiosa y completa que contenía, etcétera.

Era el más español. Aquí todos los españoles leíamos eso, el noventa por ciento de los españoles leíamos el Diario de la Marina. Además, porque traía. . era un diario de los mejores del mundo y entonces allí le traía a usted de España todos los días todo lo que pasaba en España... Todo el comercio recibía el Diario de la Marina, tó el mundo. ${ }^{90}$

La lectura de este diario le reportaba al inmigrante un conocimiento completo de los acontecimientos ocurridos y de las fiestas, homenajes, veladas, romerías. . etc., a celebrar por cada sociedad y quizá mejor que ningún otro podía servir de gaceta de las actividades de cada uno de los centros y asociaciones españolas.

Siempre tuve el Diario de la Marina. . Porque traía un rotograbado muy bonito y era el más ligado que teníamos a las sociedades españolas. ${ }^{91}$

Otros periódicos leídos por el inmigrante fueron, por orden de preferencias, El Mundo, El País, La Lucha, Información y Prensa Libre, entre otros, así como las revistas Política Cómica, Carteles, etc. Este tipo de prensa de carácter más liberal y menos reaccionaria, a juicio de nuestros entrevistados enfatizaba menos y según otros, carecía de información referente a la colectividad española, lo cual era determinante para la lectura o no de un periódico.

El Mundo era un periódico que valía tanto como el Diario de la Marina aunque no tuviese las ediciones tan lujosas porque era más popular, se acercaba más al pueblo.. Pero El Mundo no me gustaba a mí mucho porque era un poco, era un poco. . ., es decir, tenía tendencia a orillar un poco a los españoles. ${ }^{92}$

90 Entrevista núm. 322, La Habana, octubre de 1983.

91 Entrevista núm. 300, La Habana, octubre de 1983.

92 Entrevista núm. 341, Sobrefoz, Concejo de Ponga, Asturias, agosto de 1984. 
El inmigrante acudía con relativa frecuencia al teatro, al cine y a la zarzuela: "Iba mucho a la zarzuela, me costaba treinta centavos y la ópera un peso, pero arriba, en el gallinero". ${ }^{39}$

"Me metía allí en un cine que era a las doce de la noche. . y . . . hasta las tres de la mañana. Por lo demás, una vez de vez en cuando. No tenía tiempo pa eso... Apenas salía." 94

El teatro representó para estos hombres, residentes en grandes ciudades, uno de los lugares más habituales de esparcimiento, teatro Payret, teatro de la Comedia, teatro Actualidades, teatro Nacional (propiedad del Centro Gallego de La Habana), Teatro Albisu (del Centro Asturiano de La Habana), teatro Martí, teatro Heredia y teatro Alhambra, entre otros. "Yo he visto aquí en La Habana, por aquí desfilaron todos los artistas famosos del mundo y de España. . Aquí había seis $u$ ocho teatros, todos ellos con compañías españolas." 95

La representación de obras españolas, rasgo apuntado por todos los entrevistados, al igual que los precios módicos de la entrada, sobre todo en el "gallinero", animaban y posibilitaban la ida a estos espectáculos. Algunos de ellos nos confiesan haber asistido gracias a formar parte de la clac:

Yo pertenecía a la clac. Allí cuando llegaban zarzuelas, compañías, para buscar público, pues había siempre una clac. Nos daban entrada para que pasáramos, nos distribuían allí y la misión era... aplaudir. ${ }^{96}$

Uno de los teatros preferidos fue el teatro Alhambra donde las comedias con cierto tono picaresco hacían de él uno de los lugares más preciados y cuyo recuerdo todavía hace sonreír a los entrevistados. Entre los géneros representados en él destacaba el sainete, de gran aceptación popular por su tono costumbrista y desenfadado, donde todos los problemas nacionales eran sacados a relucir, los políticos, las prostitutas, los inmigrantes, sobre todo "el gallego", etcétera. ${ }^{97}$

Aunque algunos de los entrevistados calificaban a este teatro y a sus representaciones de obscenas, la mayoría no dejaban de reconocer su asidua asistencia. Pero dejemos que uno de ellos nos hable de él:

Yo era acabadito de venir aquí, tenía trece años, entonces unos amigos de alli, de casa, pues me llevaron. Eso fue una, para mi fue una sensación tremenda, allí las mujeres salían desnudas [y] todo y siempre hablaban con picardía. Vaya, con doble sentido. Muy bonito, muy bonito era. ${ }^{98}$

Al teatro Alhambra, bueno aquello era el teatro del relajo, compañera. Allí se criticaba a una cosa y a otra, al gallego, al cubano, versaba sobre la popularidad. Aquello era un teatro cómico en la calle Trocadero. ${ }^{99}$

93 Entrevista núm. 210, Sada, La Coruña, julio de 1983.

94 Entrevista núm. 303, La Habana, octubre de 1983.

95 Entrevista núm. 322, La Habana, octubre de 1983.

96 Entrevista núm. 341, Sobrefoz, Concejo de Ponga, Asturias, agosto de 1984.

97 Véase la obra de Eduardo Robreño, Como lo pienso lo digo, La Habana, Ediciones Unión, 1985, en la que el autor da una rápida visión de la evolución del teatro en Cuba desde el siglo XIX al XX.

98 Entrevista núm. 281, La Coruña, septiembre de 1983.

99 Entrevista núm. 233, Pontevedra, julio de 1983. 
En este teatro la figura del inmigrante español, del gallego, era uno de sus principales componentes junto con el negro y la mulata, al igual que en el teatro bufo cubano. Tales representaciones en que el gallego aparecía como el ignorante, usurero y tosco dentro de un tono jocoso, lejos de irritar a los espectadores de tal manera escenificados, contribuyeron a darle popularidad. 